\title{
Efficiency of the Ethiopian Health Extension Program: An Application of Data Envelopment Analysis
}

\author{
Yibrah Hagos GEBRESILASSIE ${ }^{*}$, Phocenah NYATANGA ${ }^{* *}$
}

\begin{abstract}
This study aims at evaluating the relative technical efficiency and productivity of the Ethiopian rural health extension program, with an emphasis on rural health posts, using Data Envelopment Analysis and the Malmquist index for data obtained from regional health bureaus in Ethiopia, covering 1,552 health posts for the period 2013-2014. We also examine factors associated with technical inefficiency variations across health posts using the Tobit regression model. Our findings indicate that about 5.67 percent of health posts are technically efficient. Estimated technical and scale efficiency levels of health posts vary across regions and most of them exhibit decreasing returns to scale. The examined health posts improved their productivity by 22.9 percent because of technological progress. Furthermore, supportive supervision, the average distance from health posts to households' residence, the religion and region of residence of health extension workers, were the major determinants of technical inefficiency variations across health posts. Hence, this study confirms the existence of variations in technical and scale efficiencies of health posts across and within regions, suggesting potential for improving efficiency. We, therefore recommend that the Ethiopian health posts need to augment their scale size and improve their managerial practices to enhance their overall efficiency and productivity.
\end{abstract}

Keywords: Data envelopment analysis; Efficiency; Ethiopia; Health extension workers; Health posts; Region

JEL Code Classification: I12, I15, I18, I120, 055

UDC: 614.39(63)

DOI: https://doi.org/10.17015/ejbe.2017.019.06

\footnotetext{
* Corresponding Author, Department of Economics, College of Business and Economics, Adigrat University, Ethiopia. Email: yibhag@gmail.com

${ }^{* *}$ School of Accounting, Economic and Finance, College of Law and Management Studies, University of KwaZulu-Natal, South Africa. Email: Nyatanga@ukzn.ac.za
}

Copyright (C), 2017 International Ataturk Alatoo University. 


\section{Introduction}

Evaluating the performance of healthcare systems has become a top agenda item for policy makers and practitioners (Eunice, 2013). Provision of reasonable basic healthcare services makes a considerable contribution to the overall development of a country (Gibril J. et al., 2015). However, in a globalized world, getting adequate resources for countries to sustain finance for their healthcare systems becomes a very challenging factor (Eunice, 2013). Moreover, growing populations in the context of limited healthcare resources makes it a challenge for healthcare systems across the globe to provide basic healthcare (Gibril J. et al., 2015). This challenge is more serious in less developed countries, like Ethiopia, where it is difficult to extend basic healthcare facilities to meet the needs of their populations.

Ethiopia is characterized by primary healthcare facilities that are inaccessible due to inadequate public expenditure, poor provision of a healthcare system, underdeveloped infrastructure and a lack of health personnel in the rural settings (Bilal et al., 2011; USAID, 2008). As a result, the healthcare system is unable to serve the country's largely rural population (FMoH, 2010). In response to these problems, and recognizing the widening gap between the need for healthcare and poor healthcare service provision, it was in 2004 that the Ethiopian government introduced a new health program known as Health Extension Program (HEP) at a national level as a structural reform of the national healthcare system. The goal was to improve health outcomes through providing accessible and equitable basic healthcare services to the large population of the country (CNHDE, 2011; Dynes et al., 2012; HEPCAPS1, 2012). The program makes use of Community Health Workers (CHWs), known as Health Extension Workers (HEWs), to provide basic healthcare services and health promotion at village health posts (HPs) on a door-to-door, community outreach and health post basis with especial focus on child and maternal health $(\mathrm{FMoH}, 2015, \mathrm{FMoH} 2013 / 14)^{1}$. HEWs are selected from their own communities. After they are given extensive training for a solid 12 months in both theoretical and practical aspects of basic healthcare services, they are then deployed in pairs per every village and attached to each village's health post as government-salaried health extension workers (FMoH, 2015). Since 2004 more than $38,000 \mathrm{HEWs}$ have been trained and deployed to over 16,000 health posts across regions of Ethiopia (FMoH, 2015).

Ethiopia's HEP is one of the biggest CHW programs in the world (Perry et al., 2013) and variations in healthcare services coverage across regions is a feature $(\mathrm{FMoH}$, 2015). The technical efficiency of a decision-making unit's performance is an important indicator (Hailu \& Tanaka, 2015), but there is very limited locally available literature that explores the efficiency of the program at a national level.

\footnotetext{
${ }^{1}$ A health post is a healthcare satellite unit in rural villages (kebelles) of Ethiopia in which the community health extension workers provide healthcare services as part of the health extension program targeting households in communities with between 3,000 to 5,000 , people in order to improve their overall health status (CNHDE, 2011)
} 
Therefore, measurement of the efficiency of the Ethiopian health extension program is very important to gain insights into the achievement of the program as well as to implement policy measures to improve the potential outputs level within the context of limited health inputs. In other words, how well the program is doing in achieving its overall goal in terms of the actual quantitative measures of healthcare services outputs relative to the potential attainable measures of healthcare services outputs, given the limited health inputs, is not yet thoroughly evaluated. The disparities in the health outcomes of different healthcare systems resulted from variations in their efficiency performance (Kathuria \& Sankar, 2005; Murray \& Frenk, 1999). Most importantly, among available published empirical studies, due attention has been given to the estimation of the efficiency of hospitals (Peacock et al., 2001; Worthington, 2004), but it is hard to find published community-based health worker program efficiency studies.

Prior empirical studies on the efficiency performance of the Ethiopian health extension program are limited in their scope (San Sebastian and Lemma, 2010). This study was conducted in Ethiopia's Tigrai region in 2007 and was subject to serious limitations; namely, it was carried out at a micro-regional level; and efficiency was measured at an infant stage of the program and might not indicate the real impact of the program. A community-based health worker program should have ample implementation time before an effective evaluation can be made (WHO, 1989) and, most importantly, the number of HEP beneficiary graduates were missed as an important output variable. Prior to the findings of this current study, evidence on the relative efficiency of health posts in major regions of Ethiopia at a national level were limited. To address this important gap, the aims of this study are twofold; namely, (i) to evaluate the relative technical efficiency and productivity of the Ethiopian rural health extension program, and (ii) to identify factors that explain technical inefficiency variations across health posts. This study could contribute to the limited Data Envelopment Analysis (DEA) literature in providing empirical evidence to policy makers with a wealth of information for driving improvements, to strategically direct resources to the areas that were previously underserved, and provide a platform for regions to share lessons and best practices to better serve the diverse health needs of the large rural population, and, finally, save millions of lives.

The remainder of the paper is structured as follows. A summary of the literature review is presented in section two. In section three, data and methodology are described, followed by the study's empirical findings and analysis in section four. Section five concludes the findings of the paper.

\section{Review of related literature}

Previous empirical studies on the measurement of healthcare system efficiency evaluation are well documented in developed countries. For example, a study by Aristovnik (2015) examined the healthcare system efficiency of old (EU-15) and 
new (Eu-13) member states in the European Union (EU) for a total of 151 countries using an output-oriented DEA technique. The results indicated that 27 percent and 53 percent of the EU-15 member states were efficient based on constant returns to scale (CRS) and variable returns to scale (VRS) VRS DEA models, respectively, while 38 percent and 60 percent of the EU-13 member states were found to be technically efficient based on CRS and VRS DEA models, respectively. The study further shows that there were significant differences in technical efficiency scores across regions. Similarly, there were significant variations within the efficient regions of their respective countries in the provision of healthcare services. Aristovnik's findings indicated that the most efficient regions were found in Sweden, Portugal, the Netherlands, Greece, and Spain, old EU members states, and most of them were characterized as being developed rural areas that were relatively less populated, while most of the inefficient regions were predominantly capital regions (large cities). There were some regions that were extremely technically inefficient as they were utilizing above-average healthcare inputs to produce below-average health outcomes. Hence, Aristovnik suggested that there was potential room to improve most of the inefficient EU regions by optimum use of their health inputs (Aristovnik, 2015).

Measurement of efficiency and productivity of production units (such as community-based health workers programs, as in the Ethiopian health extension program) has not received due attention in most previous health-related efficiency measurement studies. Moreover, despite the availability of much literature on health-related efficiency measurement studies that have used the DEA technique, most of them have focused on evaluation of technical efficiency of hospitals (Cheng et al., 2015; Kakeman et al., 2016; Kirigia \& Asbu, 2013; Mogha et al., 2014a, 2014b; Mogha et al., 2016). Accordingly, the previous health-related efficiency studies reviewed below indicate that Data Envelopment Analysis (DEA) has been abundantly applied to evaluate various primary production units (decision-making units).

In Africa, the application of DEA in the health sector has been quite limited, but the DEA technique has been applied in a few countries to evaluate the efficiency of health facilities. For instance, Kirigia et al. (2004) examined the technical efficiency of 32 public health centers in Kenya using the DEA efficiency estimation technique. The findings demonstrated that 56 percent of the public health centers were found to be technically inefficient, while the remaining 44 percent were technically efficient, with a different magnitude of technical efficiency scores. More importantly, the average technical efficiency score of the technically inefficient health centers was 65 percent. This suggests that, on average, they could reduce 35 percent of their current level of inputs consumption to produce the present level of output. The technically inefficient health centers had an average scale efficiency score (SE) of 70 percent, suggesting they could produce 30 percent more output with the current level of inputs, with average technical efficiency estimates of 65 percent (Kirigia et al., 2004). 
Kirigia et al. (2011) applied the DEA technique to analyze relative efficiency of 36 "maternal and child health posts" (MCHPs), 22 "community health centers" (CHCs) and 21 "community health posts" (CHPs) in Sierra Leone, using cross-sectional data of 2008. The findings revealed that there were significant variations in technical and scale efficiencies across and within the health units. The study indicated that 77.8, 59.1, and 66.7 percent of MCHP, CHC and CHPs were technically inefficient under a VRS assumption, respectively (Kirigia et al., 2011).

An assessment of the technical efficiency of 20 "Center de Sante'et d Promotion Social" (CSPS) in the Nouna health district in Kossi province in Burkina Faso was conducted by Marschall and Flessa (2009a) using the DEA technique. The findings revealed that there were considerable variations in technical efficiency scores across the CSPS. About 70 percent of the CSPS were found to be technically and scale efficient, while the remaining 30 percent were technically inefficient. The study also examined the determinants, which might affect the relative technical efficiency of the health centers using the Tobit regression model. The regression results indicated that distance to health centers affects the technical efficiency of the health centers. That is, the closer the village to the health centers, the greater the efficiency level of the health center will be. Thus, the findings indicated that the relatively technical efficient health centers were placed near to their catchment basin of the village. Likewise, health unit level evaluations of technical efficiency in the Pujehun districts of Sierra Leone using data development analysis were made by Renner et al. (2005). Of the total 37 periphery health units, 41 percent of them were technically efficient with an average level of scale efficiency of 72 percent, while 59 percent of them were technically inefficient with an average technical efficiency score of 63 percent. Overall, the average technical efficiency score of the health units was 78 percent, while the average scale efficiency was 82 percent. Due to inappropriate scale size, 65 percent of the health units were scale inefficient, with a mean scale efficiency score of 72 percent.

Another health center level study in Seychelles by Kirigia et al. (2007) evaluated the relative efficiency and productivity of 17 health centers for the period 2001 to 2004 using the DEA model and the DEA-based Malmquist productivity index. They indicated that there were significant variations in technical and scale efficiency estimates across health centers. Overall, the average technical and scale efficiency of health centers were 93 percent and 91 percent during the examined periods, respectively. They found that about 59 percent, 47 percent, 53 percent and 59 percent of the health centers were relatively technically efficient for 2001, 2002, 2003, and 2004, respectively. The mean scale of efficiency levels of the health centers was 90, 93, 92, and 95 percent for 2001, 2002, 2003, and 2004, respectively. The findings also indicated that there were significant variations across health centers' levels of productivity. In Seychelles, the overall productivity increased only by 2.4 percent during the examined periods, and the improvement in the productivity growth was due to the technological progress of the health centers during the course of the study periods (Kirigia et al., 2007). 
In Latin America, a study by Herna'ndez and Sebastia'n (2014) using the DEA technique for 34 sample health posts from 19 districts in Alta-Verapaz in Guatemala for the years 2008 and 2009, evaluated the technical efficiency of health posts. Also, they used the DEA-based Malmquist productivity index to examine productivity change at the health posts over the time periods. Overall, the technical efficiency of the health posts differed over time, and in 2008, the average technical efficiency score was 78 percent, while in 2009 the average technical efficiency score for the health posts was 75 percent. About 44 percent and 65 percent of health posts were also found to be scale inefficient in 2008 and 2009, respectively, and all exhibited decreasing returns to scale. Results of the Malmquist index showed that the overall productivity of the health posts increased by four percent during the study periods mainly due to an increase in healthcare services output. About 53 percent of the health posts improved their productivity efficiency. while the remaining 47 percent of them decreased productivity (Herna'ndez \& Sebastia'n, 2014).

Moreover, most previous health extension program studies in Ethiopia failed to focus on the efficiency and productivity of the program at the macro level. The only local study, by Lemma and Sebastian (2010), examined the technical efficiency of 60 sample health posts from seven rural districts in the Tigrai region in Ethiopia in 2007 using the DEA technique. About 25 percent of the health posts were technically efficient, and it was pointed out that there were high variations in technical and scale efficiency across the health posts evaluated. The overall average technical and scale efficiency estimates for the health posts were 57 and 95 percent, respectively. However, the study was carried out at a micro-regional level; efficiency of the health posts was evaluated at an infant stage of the program, which might not indicate the real impact of the program; productivity was overlooked; and most importantly, the health extension program beneficiary graduates were missed as an important output variable (Lemma \& Sebastian, 2010) $)^{2}$.

Therefore, the above-reviewed literature indicates that relative efficiency and productivity changes for the Ethiopian health extension program with an emphasis on health posts have not yet been studied at the macro level. Hence, analysis of relative technical efficiency and changes in productivity of the program can provide basic worthwhile information to re-engineer or redesign the national policy, strategy and programs for the health sector, with an emphasis on the health extension program so as to improve access to and utilization of healthcare services, and, finally, ensure universal healthcare services coverage across the country.

\footnotetext{
2 "Productivity is an absolute concept, measured by the ratio of outputs to inputs, while efficiency is a relative concept, measured by comparing the actual ratio of outputs to inputs with the optimal ratio of outputs to inputs" (SCRCSSP, 1997).
} 


\section{Data and Methods}

\subsection{Data}

We used cross-sectional secondary data for the years 2013 to 2014, which were obtained from the annual health statistics report of the seven regional health bureaus of Ethiopia for 1,552 health posts (HPs); namely, Tigrai, $n=161$; Amhara, $\mathrm{n}=321$; Oromia, $\mathrm{n}=601$; Southern Nations, Nationalities and People (SNNP), n=266; Gambella, $n=52$; Benshangul-Gumuz (BG), $n=129$; and Harar, $n=22$, where $n$ represents the subsample size of health posts in their respective regions under study. The health posts are satellite health centers (units of the health system) where the health extension workers perform their healthcare service delivery to their respective communities. Since the inception of the HEP in 2004, there has been a significant increase in the total number of the health posts. A total number of health posts were built reached to 14,781 by $2013 / 14$. Accordingly, Tigrai, Amhara, Oromia, SNNP, Gambella, BG, Harar, Afar, and the Ethiopia-Somali regions had $672 ; 3,317 ; 6,317 ; 3,835 ; 111 ; 384 ; 33 ; 378$ and 1,062 health posts, respectively. Similarly, the cumulative number of health extension workers has increased to more than 38,000 (FMoH, 2013/14a).

\subsection{Selection of inputs and outputs}

Three types of variables are important in evaluating the efficiency of the health posts. These are health input variables, output variables, and the "non-health system" determinants (Evans et al., 2001; Kathuria \& Sankar, 2005; WHO, 2000). The selection of health input and output variables is a crucial step for the successful employment of the DEA technique (De et al., 2012). Thus, selection of health input and output variables to measure the efficiency of the health posts was guided by a review of previous DEA studies (Herna'ndez \& Sebastia'n, 2014; Kathuria \& Sankar, 2005; Lemma \& Sebastian, 2010; Renner et al., 2005), as well as availability of comprehensive data and was guided by the objectives of the Ethiopian health extension program (FMoH, 2006/07). Therefore, this paper evaluates the technical efficiency and productivity changes of health posts using two health input and six output variables. The two health input variables are the number of (i) health extension workers (HEWs), and ii) health development armies (HDAs). The six output variables are the number of (i) the health extension program (HEP) beneficiary graduates, (ii) rural households visited by HEWs, (iii) health education sessions provided by HEWs, (iv) child delivery by HEWs, (v) child delivery by HDAs, and (vi) under-five children who are fully immunized. Furthermore, we have used "non-health system" determinants as explanatory variables to analyze variation in the technical efficiency across health posts.

\subsection{Description of explanatory variables}

The independent variables used in this paper are: (i) percentage of population served per HEW (PPHEW), (ii) the provision of in-service refresher training courses 
given to HEW (RTHEW), (iii) average distance from health post to rural households' residence (where a HEW provides the healthcare services) in Km (DVHP), (iv) years of working experience as health extension worker (YWHEW), ( $v$ ) the provision of reward based on HEW's performance (RPHEW), (vi) age of HEWs (AGHEW), (vii) marital status of HEWs (MSHEW), (viii) monthly income of HEW (MIHEW), (ix) supportive supervision provided to HEWs at least twice a month (SSHEW), $(x)$ HEW's region of residence (RRHEW) as regional dummies to control the effect of geographical locational differences on technical efficiency, (xi) religion of HEWs (RLHEW), and (xii) availability of basic medical equipment at health posts (ABME).

\subsection{Data Envelopment Analysis (DEA) analytic framework}

Efficiency can be evaluated using the two most commonly employed efficiency estimation techniques known as "frontier analysis". These are Data Envelopment Analysis (DEA) and Stochastic Frontier Analysis (SFA) (Jacobs et al., 2006). The SFA and DEA frontier approaches have their own distinguishing features. SFA is a parametric frontier approach that has a stochastic nature while formulating functional form about the relationship between health inputs. DEA, on the other hand, is a nonparametric approach that does not make any assumptions on the functional form on how input and output variables are related. In contrast to SFA, DEA can simultaneously handle multi-inputs and multi-outputs with each being expressed in different units of measurement (Charnes et al., 1978; Coelli et al., 1998). Moreover, it computes relative efficiency of units in the absence of price information for health input and output variables (Ray, 2004). To exploit these advantages, the present study makes use of the DEA model to evaluate the relative efficiency of the Ethiopian health extension program.

Generally, efficiency and productivity measures using the DEA model are computed using a linear programming function that compares similar units using a set of health inputs to produce a set of outputs. The DEA model identifies how well a health post is operating relative to its peers, not to a "theoretical maximum" benchmark (Worthington, 2004). The efficiency frontier identifies the boundary to a series of possible observed production levels and the extent to which DecisionMaking Units (i.e. health posts) lie below or above the efficiency frontier (Cooper et al., 2007; Jacobs et al., 2006). The estimated efficiency frontier consists of efficiently performing health posts and is supposed to dominate (envelop) the other health posts that remain below the efficiency frontier and in relative terms are performing inefficiently (Jacobs et al., 2006). The DEA has been extensively used in developed countries to evaluate the efficiency of various aspects of national healthcare systems (Ozcan \& Bannick, 1994; Hollingsworth \& Parkin, 1997); however, most healthcare efficiency studies have focused on the efficiency of hospitals relative to the efficiency of primary healthcare programs (Marschall \& Flessa, 2009a). Likewise, though primary healthcare programs, like the Ethiopian health extension program, have received considerable emphasis as a means of healthcare intervention all over the world to implement the health policy of a 
Efficiency of the Ethiopian Health Extension Program: An Application of Data Envelopment ...

country (Amado \& Santos, 2009), very limited studies have been carried out on the efficiency of the programs using the DEA model in developing countries (Marschall \& Flessa, 2009a).

\subsubsection{Charnes, Cooper, and Rhode (CCR) DEA approach}

We applied a two-stage DEA model to measure the relative efficiency of health posts in this study. This model is a pioneering seminal work by Farrell (1957). The DEA has been popularized by Charnes et al. (1978) and delivers a flexible nonparametric principle for empirical production analysis. In the first stage, the DEA model estimates the efficiency of health posts, while in the second stage, these estimated technical efficiencies are regressed against contextual variables by employing regression models. The DEA techniques under the CRS assumption known as the CCR (Charnes et al., 1978) DEA model computes the efficiency of health posts, based on the ratio of all outputs produced to all health inputs employed by health posts (Charnes et al., 1978). Thus, the CCR DEA computes technical efficiency assuming the health posts are operating at optimal scale size.

\subsubsection{Banker, Charnes, and Cooper (BCC) DEA approach}

BCC (Banker, Charnes \& Cooper, 1984) have formulated the DEA model based on the VRS specification as an extension of the CCR DEA model by adding a convexity constraint $\left(\sum_{i=1}^{h} v_{i} I_{i j}=1\right)$ into the system of the CCR DEA model. It considers increasing (IRS), constant (CRS), and decreasing (DRS) returns to scale. Besides, the BCC DEA model provides a decomposition of the CCR DEA Farrell efficiency measure into technical and scale efficiency. In contrast to the CCR DEA model, the BCC DEA model computes the pure technical efficiency of a health post at a given scale size (Cooper et al., 2006).

Consider a health post employs ' $h$ ' multi-health inputs, $I=\left(I_{1}, \ldots, I_{h}\right)$ to produce ' $y$ ' multi-outputs, $O=\left(O_{1}, \ldots, O_{y}\right)$. The $j^{\text {th }} \mathrm{HP}\left(O_{p}, I_{p}\right)$ is expressed in terms of vectors of health inputs and outputs in a way that $H P_{j}(\mathrm{j}=1, \ldots, \mathrm{n})$, where: $I_{i j}$ is the observed i-type quantity of the health input being consumed by $j^{\text {th }} \operatorname{HP}\left(I_{i j}>0, i=\right.$ $1, \ldots, h ; j=1, \ldots, n)$ and $O_{k j}$ is the observed k-type quantity of output produced by $j^{\text {th }} \mathrm{HP}\left(O_{k j}>0, k=1, \ldots, y ; j=1, \ldots, n\right)$. Thus, the Farrell output-oriented CCR (Charnes et al., 1978; Kengil et al., 2010) and the BCC (Banker et al., 1984) DEA models are given by $^{3}$ :

\footnotetext{
${ }^{3}$ An output-oriented assumption was preferable in this study because the national Ethiopian policy for the health extension program focused on using the available limited-resources keeping these constant while increasing the extent of healthcare services provision across region (FMoH, 2013/14b).
} 


\section{Specification of DEA models}

CCR DEA model:

$\operatorname{MaxTE} E_{j}^{*}=\sum_{o=1}^{y} u_{k} O_{k j}$

$\sum_{o=1}^{y} u_{k} O_{k j}-\sum_{i=1}^{h} v_{i} I_{i j} \leq 0 ; i=1, \ldots, n$

BCC DEA model:

$$
\begin{aligned}
& \operatorname{MaxTE}_{j}^{*}=\sum_{o=1}^{y} u_{k} O_{k j}+u_{j} \\
& \sum_{\mathrm{o}=1}^{\mathrm{y}} \mathrm{u}_{\mathrm{k}} \mathrm{O}_{\mathrm{kj}}-\sum_{\mathrm{i}=1}^{\mathrm{h}} \mathrm{v}_{\mathrm{i}} \mathrm{I}_{\mathrm{ij}}+\mathrm{u}_{\mathrm{j}} \leq 0 ; \mathrm{i}=1, \ldots, \mathrm{n} \\
& \sum_{\mathrm{i}=1}^{\mathrm{h}} \mathrm{v}_{\mathrm{i}} \mathrm{I}_{\mathrm{ij}}=1 \text {, } \\
& v_{i} \geq 0, i=1, \ldots, h ; u_{k} \geq 0, k=1, \ldots, y
\end{aligned}
$$

Where: $T E_{j}^{*}$ is the estimated technical efficiency level for the $j^{\text {th }} \mathrm{HP}$ being evaluated; $I_{i j}$ stands for the quantity of the $i^{\text {th }}$ health inputs utilized by the $j^{\text {th }} \mathrm{HP}$; $O_{k j}$ represents the quantity of the $k^{t h}$ outputs produced by $j^{t h} \mathrm{HP} ; u_{j}$ is free in sign; and $u_{k}$ and $v_{i}$ represent optimized weight for the $k^{\text {th }}$ output and to the $i^{\text {th }}$ health input, respectively ${ }^{4}$. The weights are unique to each health post in order that the computed efficiency level to be bounded between zero and unity $\left(0<T E_{j}^{*} \leq 1\right)$ depends on the distance between the efficiency frontier and health posts (Charnes et al., 1978; Farrell, 1957; Jacobs et al., 2006; Kumar \& Gulati, 2008). Thus, the computation was executed on the same data under both the CCR and BCC DEA models to compute the scale efficiency of health posts.

\subsubsection{Measuring scale efficiency}

Banker et al. (1984) have introduced the notion of the most productive scale size that is reliable with the relative technically efficient production on the efficiency frontier under CRS. The scale efficiency of the $i^{t h}$ health post $\left(S E_{j}\right)$ in a set of health posts $\mathrm{j}=1, \ldots, \mathrm{n}$ can be obtained by computing an output-oriented technical efficiency $T E_{j}{ }^{C R S}$ or $T E_{j}{ }^{C C R}$ and $T E_{j}{ }^{V R S} T E_{j}{ }^{B C C}$ as follows:

$S E_{j}=\frac{T E_{i}{ }^{C R S}}{T E_{j}{ }^{V R S}}=\frac{T E_{j}{ }^{C C R}}{T E_{j}{ }^{B C C}} \quad 0<S E_{j}<1$

A value of $S E_{j}$ equal to unity indicates that the health post is scale efficient, while a value of $S E_{j}$ less than unity indicates that the health post is scale inefficient. Whereas, a value of $\sum_{i=1}^{h} v_{i} I_{i j}<$ or $>1$ in the solution equation [02] shows that the health post is operating at either increasing or decreasing returns to scale (Ruggiero, 2010).

\footnotetext{
${ }^{4}$ Using DEA weights of input $\left(v_{i}\right)$ and outputs $\left(u_{k}\right)$ are calculated for each HP based on inputs and outputs that they used and produced. The DEA model looks for values for output and input weights that maximize the efficiency level of the $i^{\text {th }} \mathrm{HP}$, subject to constraints" (Jacobs et al., 2006).
} 


\subsection{Malmquist Productivity Index}

We have applied the DEA-based Malmquist productivity index (MPI) (Malmquist, 1953; Caves et al., 1982) to compute the total factor productivity changes of the Ethiopian health posts over the two-time periods examined (2013 and 2014). The total factor productivity is computed by the difference in the growth rate of outputs and the growth rate of inputs in the present period compared to the previous period under analysis. Thus, the present study adopted an outputoriented Malmquist productivity index based on the Fare et al. (1989) specification. It allows us to decompose productivity changes into technical efficiency and technical changes without requiring price information for output and input variables employed (Grifell-Tatje \& Lovell, 1996). Therefore, an output-oriented Malmquist productivity index $\left(M P I_{o}^{s, t}\right)$ that a health post transforms its inputs consumed $\left(I_{i}^{s}, I_{i}^{t}\right)$ into its outputs produced $\left(Y_{i}^{s}, Y_{i}^{t}\right)$ using production technologies of the two periods ( $s$ and $t$ ) is computed as follows:

$M P I_{o}^{s, t}\left(Y_{i}^{s}, Y_{i}^{t}, I_{i}^{s}, I_{i}^{t}\right)=\sqrt{\left[\left(\frac{D_{0}^{S}\left(Y_{i}^{t}, I_{i}^{t}\right)}{D_{0}^{S}\left(Y_{i}^{s}, I_{i}^{S}\right)}\right)\left(\frac{D_{0}^{t}\left(Y_{i}^{t}, I_{i}^{t}\right)}{D_{0}^{t}\left(Y_{i}^{s}, I_{i}^{s}\right)}\right)\right]}$

Efficiency change $=\left(\frac{D_{0}^{t}\left(Y_{i}^{t}, I_{i}^{t}\right)}{D_{0}^{S}\left(Y_{i}^{s}, I_{i}^{S}\right)}\right)$

Technical change $=\left[\left(\frac{D_{0}^{S}\left(Y_{i}^{t}, I_{i}^{t}\right)}{D_{0}^{t}\left(Y_{i}^{t}, I_{i}^{t}\right)}\right)\left(\frac{D_{0}^{S}\left(Y_{i}^{S}, I_{i}^{S}\right)}{D_{0}^{t}\left(Y_{i}^{S}, I_{i}^{S}\right)}\right)\right]^{0.5}$

A value of $M P I_{o}^{s, t}\left(Y_{i}^{s}, Y_{i}^{t}, I_{i}^{s}, I_{i}^{t}\right)$ greater than, equal to, or less than unity indicates a health post in period ' $\mathrm{t}$ ' is more efficient relative to itself in period ' $s$ ' (progress), efficiency of the health post remains constant over periods (stagnation) or it reduces its relative efficiency (deterioration) over periods (' $s$ ' and ' $t$ '), respectively (Coelli et al., 1998).

\subsection{Identifying sources of technical inefficiency}

Identifying the technically efficient and inefficient health posts should not be an end of evaluating technical efficiency and should be accompanied by identifying the causes of variations in technical inefficiencies across the health posts evaluated. Hence, to identify the inter-health post technical inefficiency variations, various approaches have been employed in the DEA literature. The most widely employed analytical tool in efficiency measurement studies is to employ two-step measure regressions (Worthington, 2004). The equivalent conversion of technical efficiency estimates obtained in the first-stage of the DEA analysis (as the dependent variable) was regressed against a set of independent variables (contextual) to estimate their impacts on technical inefficiency. Most prior empirical studies have used various approaches in their second-stage analysis to estimate the impact of factors affecting technical inefficiency estimates of production units, like health posts in the present context. Accordingly, McDonald (2009); Xenos et al. (2016); and Dutta et al. (2014) have applied the Tobit regression model in their second- 
stage analysis. Other non-health related efficiency studies have also applied the Tobit regression to identify factors explaining the efficiency variations across DMUs (Bhatia \& Mahendru, 2015; Debasish, 2006; Jayaraman \& Srinivasan, 2014; Kumar \& Gulati, 2008). Likewise, many other empirical studies have also applied an Ordinary Least Squares (OLS) regression model separately in their second-step regression analysis (McDonald, 2009; Dutta et al., 2014). As part of the secondstage analysis, the present study, therefore, makes use of the Tobit regression model.

\subsubsection{Using the Tobit regression in the second stage}

Technical inefficiency estimates obtained from first-stage DEA technique are used as a dependent variable and then are regressed against independent variables to explain factors responsible for variation in technical inefficiency estimates across health posts using the Tobit regression model ${ }^{5}$. In most DEA literature, the effect of independent variables is usually analyzed using the Tobit regression model since they have considered estimates of technical efficiency to be bounded between zero and unity (McDonald, 2009; Xenos et al., 2016).

Therefore, the Tobit regression model can be expressed as follows (see Green, 1994):

$Y_{i j}^{*}=\alpha_{0}+\alpha_{i} X_{i j}+\varepsilon_{i j} ; \quad \varepsilon_{i j} \sim N\left(0, \delta^{2}\right)$

$Y_{i j}=Y_{i j}^{*}$ if $Y_{i j}^{*}>0$;

$Y_{i j}=0 \quad$ if $Y_{i j}^{*}$ if $Y_{i j}^{*} \leq 0 ; i=1,2,3, \ldots n$

Where: $Y_{i j}^{*}$ represents a possibly censored version of $Y_{i j} ; \alpha_{0}$ represents a constant term; $\alpha_{i}$ represents the vector of unknown regression parameters; $X_{i}$ denotes the vector of independent variables (defined above); $\varepsilon$ is the random error term; and $D E A_{\text {Ineff }}\left(=Y_{i j}\right)$ represents the technical inefficiency estimates of the $i^{\text {th }}$ health post in a set of $\mathrm{j}=1, \ldots, \mathrm{n}$ health posts under analysis.

Using equation [07], the basic Tobit regression model can alternatively be stated as follows:

$D E A_{\text {Ineff }}=\alpha_{0}+\sum_{j=1}^{n} \alpha_{i} X_{i j}+\varepsilon$

Therefore, the efficiency estimation analysis using the DEA technique was computed by a computer statistical software packages known as DEAP version 2.1 and MaxDEA Pro version 6.4, as these are the most commonly used type of efficiency analysis software packages (Coelli et al., 1998; Coelli, 1996) All other statistical computations were made using STATA, version 13.

${ }^{5} \mathrm{DEA}_{\text {Ineff }}=\left(\frac{1}{\mathrm{TE}_{\mathrm{j}}^{*}}\right)-1=\frac{1}{\mathrm{TE}_{\mathrm{j}}^{*}}-\frac{\mathrm{TE}_{\mathrm{j}}^{*}}{\mathrm{TE}_{\mathrm{j}}^{*}}=\left(\frac{1-\mathrm{TE}_{\mathrm{j}}^{*}}{\mathrm{TE}_{\mathrm{j}}^{*}}\right)$ is used to compute technical inefficiency and employed as a dependent variable in the second-stage of our analysis. 
Efficiency of the Ethiopian Health Extension Program: An Application of Data Envelopment ...

\section{Empirical results}

\subsection{Estimates of technical efficiency}

Findings indicate that there is a substantial variation in technical and scale efficiency estimates across sample health posts (see Table 1 and Table 5). In 2014, health posts had better average overall technical and pure technical efficiency estimates of 58 percent and 79.6 percent, respectively. This indicates that if they were operating at optimal scale size, they would have produced at least 42 and 20.4 percent more outputs with the same levels of health inputs under CRS and VRS assumptions, respectively. In 2013, on average, health posts had an overall technical and pure technical efficiency score of 55.6 and 78.6 percent, respectively. Similarly, in 2014 the overall technical and pure technical efficiency estimates of sample health posts range from 27.3 to 100 percent, and 51.1 to 100 percent, under constant and variable returns scale assumptions, respectively. This result implies that, given the existing production technology, they could potentially increase their outputs provision by at least 72.7 to 48.9 percent with the current levels of health inputs. To put it differently, they have the scope for producing 3.66 to 1.96 times (i.e.1/0.273 to 1/0.511) as much outputs from the same levels of health inputs being consumed under CRS and VRS assumptions, respectively (see Table 1).

\section{Table 1. Average estimates of technical and scale efficiency for inefficient health posts}

\begin{tabular}{lccc}
\hline Annual average & $T E_{C R S}$ & $T E_{V R S}$ & Scale efficiency \\
\hline 2013 & $53.9[20.9,99.6]$ & $77.7[46.7,99.9]$ & $69.9[37.7,100]$ \\
Overall sample & $55.6[20.9,100]$ & $78.6[46.7,100]$ & $70.6[37.7,100]$ \\
2014 & $56.8[27.3,99.8]$ & $78.9[51.1,99.8]$ & $71.6[37.6,100]$ \\
Overall sample & $58.0[27.3,100]$ & $79.6[51.1,100]$ & $72.4[37.6,100]$ \\
\hline Sources: Authors' own computation. Note: Values in brackets are minimum and maximum technical \\
$\left(T E_{C R S}\right.$ and $\left.T E_{V R S}\right)$ and scale efficiency estimates under CRS and VRS assumptions, respectively.
\end{tabular}

In 2014, only 2.84 and 5.67 of the sample health posts were technically efficient under CRS and VRS assumptions, respectively (see Table 2). This indicates that there is significant potential for improving their technical efficiency. The technically inefficient health posts had a technical efficiency of 56.8 and 78.9 percent, with the average technical efficiency being 58 and 79.6 percent under CRS and VRS assumptions, respectively. In 2013 and 2014, the technically inefficient health posts had a scale efficiency of 70.6 and 72.4 percent, with an average scale efficiency of 70.6 and 72.4 percent under CRS and VRS assumptions, respectively (see Table 1). We have carried out a jackknife analysis while evaluating the relative technical efficiency of health posts. Accordingly, findings of the jackknife analysis revealed that efficiency estimates were not influenced by extreme outliers across the health posts evaluated, which built the efficiency frontier, as the correlation coefficients range from 84 to100 percent. 
Yibrah Hagos GEBRESILASSIE \& Phocenah NYATANGA

Table 2. Percentage of fully technically and scale efficient health posts by region, 2014

\begin{tabular}{lcccc}
\hline & & \multicolumn{2}{c}{ Fully technically efficient } & Scale efficient \\
\cline { 3 - 4 } Region & Rank & $T E_{C R S}$ & $T E_{V R S}$ & \\
\hline Tigrai & 1 & 8.69 & 19.88 & 18.63 \\
Amhara & 3 & 1.87 & 2.49 & 7.48 \\
Oromia & 2 & 3.83 & 7.15 & 9.98 \\
SNNP & 4 & 0.38 & 1.50 & 5.26 \\
Gambella & 5 & 0.00 & 0.00 & 6.69 \\
BG & 6 & 0.00 & 0.00 & 2.32 \\
Harar & 7 & 0.00 & 4.54 & 0.00 \\
\hline 2014 & & 2.84 & 5.67 & 8.70 \\
\hline
\end{tabular}

Source: Authors' own computation

In Table 2, the first column indicates the regions under analysis followed by their corresponding ranks based on a percentage of availability of fully technically efficient health posts. The third and fourth columns show the percentage of fully technically efficient health posts under CRS and VRS assumptions, respectively. The last column indicates the scale efficient health posts by percent. Findings indicate that the Ethiopian regional states considerably differ in their average levels of health inputs consumptions that yield varied healthcare services outputs for their respective health posts (see Table 2). Accordingly, results show that out of the total proportional sample of regional health posts about 8.69 and 19.88 percent; 3.83 and 7.15 percent; 1.87 and 2.49 percent, and 0.38 and 1.5 percent of health posts in Tigrai, Oromia, Amhara, and SNNP regions were fully technically efficient under CRS and VRS assumptions, respectively. They had average technical efficiency estimates of 67.5 and 84.1 percent, 60.6 and 81.6 percent, 58.1 and 77.8 percent, and 51.5 and 75.5 percent under CRS and VRS assumptions, respectively in 2014. These figures suggest that, by adopting best practice technology, health posts in the respective regions could produce more outputs by at least 32.5 and 15.9 percent, 39.4 and 18.4 percent, 41.9 and 22.2 percent, and 48.5 and 24.5 percent under CRS and VRS assumptions, respectively, using the same levels of health inputs (Table 2 and Table 5).

Relatively, health posts in the Tigrai region had the highest average technically efficiency estimates, which characterized them as relatively consuming their available health inputs in the most efficient way and as a result attaining the highest relative rank (the best performing region on technical efficiency). This might be the region that had experience of community-based healthcare services provision to the rural community during the Ethiopian civil war prior to the launch of the community-based health extension program in 2004 at the national level (Ghebreyesus, et al., 1996). Besides, this region had relatively larger technically efficient health posts, with about 8.69 and 19.88 percent of them being fully technically efficient under CRS and VRS assumptions, respectively. In contrast, health posts in the Harar region were characterized by a relatively lower mean of 
48.2 and 68.1 percent technical efficiency estimates under CRS and VRS assumptions, respectively, with relatively high input wastage attributed to their optimal scale size (poorly performing region). Besides, health posts in this region were, on average, operating below the national mean technical and scale efficiency levels under both scale assumptions. The reason why health posts in the Harar region are performing poorly might be that the program was implemented or practiced in that region only more recently. At the national level, only 2.84 and 5.67 percent of the sample health posts were fully technically efficient, with average overall technical and pure technical efficiency estimates of 58 and 79.6 percent, respectively. This result indicates high potential for improving the efficiency of the health posts. Moreover, about 8.7 percent of the sample health posts were defined as scale efficient, with a mean scale efficiency level of 72.4 percent (see Table 2).

In Africa, it is often assumed that health facilities are not very technically efficient (Marschall \& Flessa, 2009b). In addition to the findings of the present paper, most of the previous DEA studies carried out in developing countries reported the very high proportion of technically inefficient health facilities. For example, Kirigia et al. (2011) indicated that about 67 percent of the evaluated community health posts in Sierra Leone were technically inefficient. In the same country, but in a different time period, Renner et al. (2005) reported that 59 percent of the studied periphery health units were technically inefficient with a different magnitude of estimated efficiency scores. In Kenya, the paper by Kirigia et al. (2004) examined the technical efficiency of public health centers and they found that 56 percent of health centers were technically inefficient. In Latin America, for example, in Guatemala, the study by Herna'ndez and Sebastia'n (2014) examined the technical efficiency of health posts and indicated that in 2008 and 2009, about 53 and 29 percent of health posts were technically efficient. Similarly, a study by Lemma and Sebastian (2010) evaluated the efficiency of health posts in Ethiopia at the micro-regional level, and indicated that 75 percent of them were technically inefficient; however, they indicated that there were variations in technical efficiency scores across health posts. In comparison, the present study found a relatively large percentage of technically inefficiency health posts with different magnitudes of efficiency scores.

As indicated in Table 3, on average, health posts in their respective regions differ considerably in their mean scale and technical efficiency levels, indicating potential for improving their efficiency. For example, health posts in the Tigrai region had mean scale and technical efficiency levels of 67.5 and 84.1 percent under CRS and VRS assumptions, respectively. Health posts with relatively high mean technical and scale efficiency estimates were also found in this region, with mean VRS technical and scale efficiency levels of 84.1 and 79.7 percent. Likewise, relatively, health posts in the Harar region had the lowest mean technical efficiency levels. The present findings firmly indicate that technical efficiency estimates for health posts vary across regions, suggesting great potential for improving the efficiency of the program. This finding could be justified by the majority of sample health posts (91.24\%) exhibiting DRS as a major form of scale inefficiency. 
Yibrah Hagos GEBRESILASSIE \& Phocenah NYATANGA

Table 3. Average percentage of technical and scale efficiency of health posts by region, 2014

\begin{tabular}{lccclcc}
\hline & \multicolumn{3}{c}{ Technical and scale efficiency } & \multicolumn{3}{c}{ Health posts operating at: } \\
\cline { 2 - 7 } Region & $T E_{C R S}$ & $T E_{V R S}$ & SE & DRS & CRS & IRS \\
\hline Tigrai & 67.5 & 84.1 & 79.7 & 81.37 & 18.63 & 1.24 \\
Amhara & 58.1 & 77.8 & 74.4 & 92.52 & 7.48 & 0.62 \\
Oromia & 60.6 & 81.6 & 73.7 & 89.85 & 10.15 & 0.33 \\
SNNP & 51.5 & 75.5 & 68.1 & 94.74 & 5.26 & 0.38 \\
Gambella & 52.2 & 84.0 & 61.7 & 92.31 & 7.69 & 0.00 \\
BG & 51.0 & 77.5 & 65.7 & 97.77 & 2.32 & 0.00 \\
Harar & 48.2 & 68.1 & 70.7 & 100.00 & 0.00 & 0.00 \\
- Mean & 58.0 & 79.6 & 72.4 & 91.24 & 8.76 & 0.45 \\
\hline
\end{tabular}

Source: Authors' own computation

\subsubsection{Estimates of scale efficiency}

Overall, about 91.3 percent of health posts were scale inefficient while the remaining 8.7 percent of them were scale efficient, with the overall mean scale efficiency level being 72.4 percent. This estimate implies that there is a possibility of augmenting the total outputs by about 27.6 percent using the existing scale size (capacity) of the health posts if they operated on an efficiency frontier (see Table 3). The mean scale efficiency estimates indicate that relatively many scale efficient health posts (18.63) were found in Tigrai region. This region consistently had more of the efficient health posts and took the lead with a mean scale efficiency level of 79.7 percent, followed by Oromia and Amhara regions, which had about 10 and 7.48 percent scale efficient health posts, with mean scale efficiency levels of 73.7 and 74.4 percent, respectively. These figures imply that, on average, scale inefficient health posts in the Tigrai, Oromia and Amhara regions have the scope to increase their outputs provision by about 20.3 percent, 26.3 percent, and 25.6 percent by downsizing their scale size, respectively. Though the average scale efficiency level was about 70.6 percent, a high proportion of scale inefficient health posts were found in Harar region (100 percent) followed by Benshangul-Gumuz (97.68 percent) and SNNP (94.74) regions (see Table 2).

The regional health posts significantly differ in their returns to scale. Overall, though most of the health posts in the sample were operating at DRS (supraoptimal scale), which is the major form of scale inefficiency in this particular study, there was a significant difference across regional health posts in their returns to scale. The majority, 91.24 percent of health posts under analysis, were operating at DRS, implying that they could potentially increase their current technical efficiency levels by the downsizing of their scale size to strive for the most productive scale size. Moreover, about 8.31 percent of health posts were operating at CRS (optimal scale). However, very few health posts were operating at IRS (sub-optimal scale size), suggesting that they could increase their technical efficiencies by augmenting their scale size (see Table 3). 
Most of the previous DEA studies carried out in developing countries reported a very small proportion of scale efficient health facilities. In this paper, overall only 8.7 percent of the health posts were scale efficient, with a very high percentage, 91.3 percent of health posts being scale inefficient with different proportions of scale efficient health posts across regions (see Table 2). In Sierra Leone, 36 percent of health posts were scale inefficient (Kirigia et al., 2011); in Guatemala, about 44 and 65 percent of health posts were also found to be scale inefficient in 2008 and 2009, respectively (Herna'ndez \& Sebastia'n, 2014); in Gambia, 90 percent of health centers were scale inefficient (JarJuEa et al., 2015); and in Sierra Leone, 65 percent of the health units were scale inefficient (Renner et al., 2005). However, in the present paper, there was a high percentage of scale inefficient health posts (91.3 percent), this being more than those of the above-mentioned countries' health facilities.

\subsection{Improving universal healthcare services coverage}

The inefficient health posts could potentially improve their relative technical efficiency estimates by either reducing their present levels of health inputs while producing the same level of outputs or vice versa or reducing inputs and at the same time increasing outputs. Accordingly, the average number of HEWs needs to be reduced by the inefficient health posts in the SNNP region (1.72 percent), followed by Benshangul-Gumuz region (2.48 percent) at very minimum level. Whereas the average number of HDAs needs to be reduced by inefficient health posts in the Amhara region (10.86 percent), followed by Tigrai region (12.32 percent) to make them efficient at very minimum levels. Thus, they could become efficient by reducing their low levels of health inputs that were being wasted.

Consider for example the technically inefficient health posts in the Tigrai region, where they could, on average, possibly reduce the number of HEWs and HDAs employed by 6.5 and 12.32 percent, respectively. The proportional reductions in health inputs alone would not make them technically efficient unless accompanied by simultaneously augmenting their current levels of outputs production. Thus, concurrently, they have to potentially produce more outputs: the number of HEP beneficiary graduates, households visited by HEWs, health education sessions provided by HEWs, child delivery by HEWs, child delivery by HDAs, and under-five children fully immunized by 40.03; 31.68; 28.83; 63.10; 52.82 and 35.01 percent, respectively, to propel them to a more productive scale size point. Similar explanations could be extended for other inefficient health posts in the remaining other regions under analysis.

In 2014, national level efficiency analysis indicated that, on average, health posts would need to reduce both the number of HEWs and HDAs employed by 4 and 20.44 percent, respectively, compared to 2013, implying that they appear to be major sources inefficiencies. Concurrently, they could possibly augment their current levels of outputs, including the number of HEP beneficiary graduates, 
households visited by the HEWs, health education sessions provided by HEWs, child delivery by HEWs, child delivery by HDAs, and under-five children fully immunized by 43.81 ; 54.77 ; 34.04; 48.09; 32.22; and 29.17 percent, respectively. The number of households visited by HEWs (54.77 percent) followed by many children delivered by HEWs (48.09 percent) were observed to be major sources of inefficiencies. There is a significant variation across regional health posts in the quantity of health inputs that need to be reduced and outputs that need to be augmented. Therefore, the present findings indicated that more basic healthcare services could be provided both at regional and national levels by improving the efficiency of the inefficient health posts, and as a result, universal health coverage could significantly be improved (see Table 4).

\section{Table 4. Average health input (output) savings (additions) needed to make HPs efficient}

\begin{tabular}{|c|c|c|c|c|c|c|c|c|c|}
\hline \multirow[b]{3}{*}{ Regions } & \multicolumn{9}{|c|}{ Potential improvements in percentage, 2013} \\
\hline & \multirow[b]{2}{*}{$\mathrm{TE}$} & \multirow[b]{2}{*}{$\mathrm{O}_{1}$} & \multicolumn{4}{|c|}{ Output gains (addition) } & \multirow[b]{2}{*}{$\mathrm{O}_{6}$} & \multicolumn{2}{|c|}{ Input savings } \\
\hline & & & $\mathrm{O}_{2}$ & $\mathrm{O}_{3}$ & $\mathrm{O}_{4}$ & $\mathrm{O}_{5}$ & & $\mathrm{I}_{1}$ & $\mathrm{I}_{2}$ \\
\hline Tigrai & 0.78 & 36.23 & 40.27 & 51.19 & 52.33 & 74.06 & 34.66 & -5.49 & -7.45 \\
\hline Amhara & 0.73 & 44.11 & 46.23 & 84.86 & 81.89 & 63.07 & 41.50 & -4.92 & -4.02 \\
\hline Oromia & 0.78 & 43.30 & 105.3 & 44.33 & 59.57 & 55.64 & 34.13 & -7.23 & -15.33 \\
\hline SNNP & 0.75 & 66.01 & 88.09 & 79.51 & 137.95 & 125.8 & 40.63 & -14.27 & -21.59 \\
\hline Gambella & 0.87 & 73.29 & 177.26 & 31.63 & 158.21 & 258 & 15.23 & -19.89 & -29.71 \\
\hline BG & 0.80 & 75.39 & 224.9 & 35.92 & 142.38 & 243.73 & 26.20 & -13.58 & -13.49 \\
\hline Harar & 0.50 & 104.85 & 143.57 & 117.75 & 562.81 & 83.86 & 100.83 & -0.25 & -17.43 \\
\hline \multirow[t]{3}{*}{ Mean } & 0.77 & 51.87 & 98.36 & 59.12 & 96.26 & 68.31 & 36.43 & -8.83 & -13.92 \\
\hline & \multicolumn{7}{|c|}{ Potential improvements in percentage, 2014} & & \\
\hline & \multicolumn{7}{|c|}{ Output gains(addition) } & \multicolumn{2}{|c|}{ Input savings } \\
\hline Region & $\mathrm{TE}$ & $\mathrm{O}_{1}$ & $\mathrm{O}_{2}$ & $\mathrm{O}_{3}$ & $\mathrm{O}_{4}$ & $\mathrm{O}_{5}$ & $\mathrm{O}_{6}$ & $\mathrm{I}_{1}$ & $I_{2}$ \\
\hline Tigrai & 0.80 & 40.03 & 31.68 & 28.83 & 63.10 & 52.82 & 35.01 & -6.50 & -12.32 \\
\hline Amhara & 0.77 & 42.17 & 53.80 & 42.89 & 49.14 & 33.11 & 30.06 & -5.99 & -10.86 \\
\hline Oromia & 0.80 & 37.31 & 59.68 & 28.96 & 36.92 & 26.93 & 25.81 & -2.80 & -21.94 \\
\hline SNNP & 0.75 & 42.13 & 49.29 & 44.91 & 58.80 & 36.35 & 34.26 & -1.71 & -21.58 \\
\hline Gambella & 0.84 & 29.21 & 70.38 & 19.09 & 47.18 & 25.87 & 19.09 & -6.09 & -40.48 \\
\hline$B G$ & 0.78 & 36.25 & 77.32 & 29.32 & 68.01 & 31.48 & 29.06 & -2.48 & -22.41 \\
\hline Harar & 0.67 & 63.96 & 121.98 & 49.61 & 162.74 & 50.52 & 52.99 & -5.20 & -33.89 \\
\hline Mean & 0.78 & 43.81 & 54.77 & 34.04 & 48.09 & 32.22 & 29.17 & -4.00 & -20.44 \\
\hline
\end{tabular}

Source: Authors' own computation. Note: TE represents technical efficiency under VRS assumption; $\mathrm{O}_{1}$ $\mathrm{O}_{2}, \mathrm{O}_{3}, \mathrm{O}_{4}, \mathrm{O}_{5}$, and $\mathrm{O}_{6}$ represent the number of HEP beneficiary graduates, households visited by HWEs, health education sessions provided by HEWs, child delivery by HEWs, child delivery by HDAs, and underfive children fully immunized, respectively (potential improvement for output gains); $I_{1}$ and $I_{2}$ denote the number of HEWs and HDAs that need to be reduced (health input savings).

\subsection{Productivity (Malmquist) Analysis}

Productivity (efficiency changes) for the Ethiopian health posts was analyzed during the years 2013-2014 using the DEA-based Malmquist productivity index. In a given time period (2014), the efficiency of these health posts was compared with the (i) 
efficiency of other health posts in the system in the same time period, and (ii) their own efficiency estimates in the previous time period (2013). Total factor productivity of the health posts can be driven by either change in efficiency ("catchup effect") or technological improvement ("Frontier shift"). Similarly, the change in total factor productivity can be decomposed into technological and technical efficiency changes, and technical efficiency change can further be decomposed into pure technical efficiency and scale efficiency changes. Table 5 shows findings of productivity change for the health posts during the time periods 2013-2014.

\subsubsection{Efficiency change}

The average efficiency change (column 1 of Table 5 ) of health posts comprises pure and scale efficiency changes. The average ratio less than unity $(0.868)$ indicates that, on average, technical efficiency of the health posts decreased by 13.2 percent, which accounts for the overall decline in the total factor productivity during the study period. According to Table 5, about 18.82 percent of sample health posts experienced technological progress, with a technical efficiency level of greater than unity. Whereas, very few of the health posts (7.02 percent) experienced technological stagnation, with technical efficiency levels equal to unity. This finding means that the production scale of these health posts did not contribute to the overall productivity change. Whereas, about 74.16 percent of them had a technical efficiency index score of less than unity, suggesting that their scale of production contributed negatively to the overall productivity change of these health posts. Our analysis further indicates that regional sample health posts had an efficiency change score of less than unity while their pure technical efficiency changes remained unchanged over the course of two years.

Table 5. Malmquist productivity index summary of annual means (20132014)

\begin{tabular}{lccccc}
\hline Region & $\begin{array}{c}\text { Efficiency } \\
\text { change } \\
(1)=3 * 4\end{array}$ & $\begin{array}{c}\text { Technological } \\
\text { change (2) }\end{array}$ & $\begin{array}{c}\text { Pure technical } \\
\text { efficiency } \\
\text { change: (3) }\end{array}$ & $\begin{array}{c}\text { Scale efficiency } \\
\text { change } \\
(4)=1 / 3\end{array}$ & $\begin{array}{c}\text { Total factor } \\
\text { productivity } \\
\text { change (5)=1*2 }\end{array}$ \\
\hline Tigrai & 0.962 & 1.232 & 1.00 & 0.962 & 1.193 \\
Amhara & 0.894 & 1.242 & 1.00 & 0.894 & 1.110 \\
Oromia & 0.889 & 1.182 & 1.00 & 0.889 & 1.045 \\
SNNP & 0.895 & 1.338 & 1.00 & 0.895 & 1.195 \\
Gambella & 0.955 & 1.440 & 1.00 & 0.955 & 1.386 \\
BG & 0.902 & 1.372 & 1.00 & 0.902 & 1.236 \\
Harar & 0.780 & 1.415 & 1.00 & 0.780 & 1.094 \\
Mean & 0.868 & 1.229 & 1.00 & 0.868 & 1.067 \\
\hline Frequency distribution (2013-2014) in percent & & & \\
\hline$>1.00$ & 18.82 & 83.76 & 0.00 & 18.82 & 60.12 \\
$=1.00$ & 7.02 & 0.20 & 100 & 7.02 & 0.19 \\
$<1.00$ & 74.16 & 16.04 & 0.00 & 74.16 & 39.69 \\
\hline
\end{tabular}

Sources: Own computation. Note: Malmquist index score $>,=$ and $<1$ indicate improvement, no change (stagnation), and reduction in productivity, respectively. 


\subsubsection{Scale efficiency change}

As column 4 of Table 5 indicates, sample health posts experienced an average reduction of the scale efficiency change index of 0.868 during the study period. This implies that, on average, the scale of production of health posts has declined slightly. Efficiency change of 13.2 percent has contributed negatively to the overall productivity growth. More importantly, findings indicate that none of the regional proportional sample health posts and overall national health posts under scrutiny attained a scale efficiency change score of greater than unity. As illustrated in Table 5 , about 74.16 percent of health posts had an estimated scale efficiency index of less than unity; this signifies that they have contributed negatively to the overall productivity change. Likewise, about 18.82 percent of them had a scale efficiency index of greater than unity, implying that the scale production of these health posts has contributed positively to their productivity change while a very small number of health posts (7.02 percent) have experienced technical stagnation, with the technical efficiency level equal to unity. This indicates that the scale of production of these health posts did not contribute to the overall productivity change of the total number of health posts.

\subsubsection{Technological and total factor productivity changes}

The average technological efficiency change (column 2) for the sample health posts was greater than unity (1.229), implying that 22.9 percent average annual technological progress, which accounts for the overall increase in the total factor productivity of the sample health posts during the study period. During the study period, about 83.76 (16.04) percent of sample health posts reported an increase (decrease) in technological change, with an index of greater (less) than unity. Furthermore, the Malmquist findings indicate that regional health posts have experienced a total factor productivity improvement (column 5) with an index of greater than unity during the panel. For example, health posts in the Gambella region have achieved their productivity growth with an estimated average annual productivity growth rate of 38.6 percent, while health posts in the Oromia region recorded the lowest result with productivity growth of 4.5 percent. Findings further reveal that there was an alarmingly high degree of variation in the size of indices of productivity changes for sample health posts across the regions examined. As column 5 of Table 5 shows, the sample health posts experienced productivity improvement (progress) with an average index of 6.7 percent, mainly due to technical progress (22.9 percent). About 60.12 (39.69) percent of health posts had a total factor productivity index of greater (less) than unity during the study periods.

In comparison with other previous studies, the overall productivity growth of the present study (6.7 percent) was a bit higher than in other studies. For example, in Guatemala, the productivity of health posts was 4 percent (Herna'ndez \& 
Efficiency of the Ethiopian Health Extension Program: An Application of Data Envelopment ...

Sebastia'n, 2014), and in Seychelles, the overall productivity of health centers was 2.4 percent.

\subsection{Sources of inter-health posts technical inefficiency}

The wide-ranging variation in technical efficiency estimates across health posts might be important to rationalize the need for examining the causes of inter-health post technical efficiency estimates variation while a high degree of consistency in technical efficiency levels among health posts would have made this study less appropriate. Accordingly, our regression findings (Table 6) indicate that in most regional health posts, there was a strong positive association and the statistically significant difference between health posts' technical inefficiency and the average distance from health posts to rural households' residence. Health posts where health extension worker provide basic healthcare services as part of the health extension program should be closer to rural households' residence, and so increase the efficiency levels of the inefficient health posts. Reducing the average distance between health posts' and rural households' residences improves the technical efficiency of health posts through effective use of health inputs, keeping other factors constant. Health extension workers could provide more basic healthcare services to large rural households by saving on long travelling distances to reach rural households. Statistically, there was a significant difference between the average distance from health posts to rural households' residences and health posts' technical inefficiency at 10 percent level of significance. This finding was in support of the studies by Bhattacharji et al. (1986) and Marschall and Flessa (2009a), which identified that longer distances to health facilities (i.e. health posts) affect positively technical inefficiency of health facilities.

Less frequent supportive supervisory visits made to HEWs was associated with the technical inefficiency of health posts, holding constant for a multitude of other determinants. Statistically, there was a significant difference between supportive supervisions provided for HEWs, and heath posts' technical inefficiency at 10 percent level of significance. Previous studies have indicated a negative relationship between continued supportive supervision provision and technical inefficiency of health facilities (Christopher et al., 2011; Condo et al., 2014; Sharma et al. (2014). Likewise, compared to a Christian HEW, being a Muslim HEW has a positive effect on health posts' technical inefficiency. That means technical inefficiency of health posts tends to increase with a Muslim HEW. The Muslim religion might not allow them to dare to provide family planning services, which might hinder performing health extension program packages efficiently. Statistically, there was a significant difference for Muslim health extension workers and health posts' technical inefficiency at 10 percent level of significance. This finding was consistent with the previous study by Christopher et al. (2011), indicating that $\mathrm{CHWs}^{\prime}$ religion could affect the technical efficiency of health facilities. 
Table 6. Determinants of inter-health posts variations in technical inefficiency

\begin{tabular}{|c|c|c|c|}
\hline & Tobit model & & Tobit model \\
\hline Variables & $T E I_{V R S}$ & Variables & $T E I_{V R S}$ \\
\hline Percentage of population served by & -0.000512 & Reference region (=Tigrai) & \\
\hline HEW & $(0.000462)$ & Region_Amhara & $0.250^{\text {*** }}$ \\
\hline In-service refresher training given & -0.00135 & & $(0.0462)$ \\
\hline to HEW (RTHEW) & $(0.0241)$ & Region_Oromia & $0.185^{* * *}$ \\
\hline Average distance from $\mathrm{HP}$ to rural & $0.0427^{*}$ & & $(0.0424)$ \\
\hline households' residence (DVHP) & $(0.0168)$ & Region_SNNP & $0.477^{* * *}$ \\
\hline Years of working as HEW (YWHEW) & $\begin{array}{l}-0.00183 \\
(0.00416)\end{array}$ & Region_Gambella & $\begin{array}{l}(0.0495) \\
0.394^{* * *}\end{array}$ \\
\hline $\begin{array}{l}\text { Performance reward_dummy } \\
\text { (RPHEW) }\end{array}$ & $\begin{array}{l}-0.0540 \\
(0.0370)\end{array}$ & Region_BG & $\begin{array}{l}(0.0641) \\
0.417^{* * *}\end{array}$ \\
\hline AGHEW $^{2}$ & $\begin{array}{l}0.0000123 \\
(0.0000639) \\
-0.0000120\end{array}$ & Region_Harar & $\begin{array}{l}(0.0509) \\
0.571^{* * *} \\
(0.122)\end{array}$ \\
\hline Monthly income of HEW (MIHEW) & $(0.0000152)$ & $\begin{array}{l}\text { Religion of } \\
\text { HEW_Muslim }\end{array}$ & $0.134^{* * *}$ \\
\hline $\begin{array}{l}\text { Supportive supervision_dummy } \\
\text { (SSHEW) }\end{array}$ & $\begin{array}{l}0.0716^{*} \\
(0.0347)\end{array}$ & Religion of HEW_Others & $\begin{array}{c}(0.0296) \\
-0.0158 \\
(0.0243) \\
\end{array}$ \\
\hline$N$ & & & 1552 \\
\hline Adj. R-sq & & & 0.080 \\
\hline
\end{tabular}

Furthermore, a region of HEWs as a dummy variable had a positive effect on technical inefficiency and was found statistically significant at 1 percent level of significance for health posts belonging to the remaining regions in reference to Tigrai region. Statistically, there were significant differences in health posts' technical inefficiency between health posts located in different regions of Ethiopia. This signifies that HEWs' region of residence significantly affects variations in technical inefficiency across health posts. Relatively, health extension workers operating in health posts in the Tigrai region affected negatively health posts' technical inefficiency (performing relatively better) compared to HEWs operating in health posts in the other regions (performing relative poorly). This implies that Tigrai regional health posts had relatively better technical efficiency estimates compared to other regional health posts under analysis. These findings are consistent with findings from studies by Bhattacharji et al. (1986); Christopher et al. (2011); and Sharma et al. (2014), who indicated that community health workers' region of residence could affect the technical inefficiency of health facilities. 


\section{Conclusion}

The Ethiopian government gives high priority to the provision of basic healthcare services to the large rural population in the country through its health extension program across its administrative regions. Hence, evaluation of the efficiency of health posts (rural health organization) where the Ethiopian health extension program is functioning in order to provide basic healthcare services to its rural population, is important for redesigning or reformulating appropriate policies, strategies, and programs to ensure universal healthcare coverage and achieve health-related national goals.

This paper aims to evaluate the relative technical efficiency and productivity of the Ethiopian rural health extension program, with an emphasis on rural health posts. The findings of the paper firmly indicate that there is a substantial variation in estimated technical and scale efficiencies across the health posts evaluated across and within regions. This variation suggests that there is significant potential for improving the efficiency of the Ethiopian health extension program through improving the efficiency of the technically inefficient health posts. Most of the sample health posts (91.24\%) exhibited decreasing returns to scale (DRS) as a major form of scale inefficiency. Hence, to make the technically inefficient health posts efficient, they would need to reduce consumed health inputs and, at the same time, they could augment all their current levels of healthcare services output provision. Furthermore, most of the health posts reported efficiency regress and as a result, their overall productivity increased by only 6.7 percent due to an improvement in technological progress during the study period. More importantly, the average distance from health posts to rural households, the health extensions workers' region of residence, and provision of supportive supervision to health extension workers were the most important determinants of inter-health posts variation in technical inefficiency.

Besides the valuable contribution of this study to the limited community-based health worker programs efficiency measurement literature, its application to the Ethiopian health sector has potential policy implications. We, therefore, recommend that the Ethiopian health posts need to augment their scale size and improve their managerial practices to enhance their overall efficiencies and productivities. This could be realized and the Ethiopian health extension program should embark on periodic research and development, and enhance basic healthcare services provision and use of health inputs (resources) in an efficient way, which would lead health posts to improve significantly their efficiency and ensure universal health coverage across all regions of the country.

However, this study is not free from limitations. From the DEA approach perspective, first, the DEA technique does not consider the error term in its functional model and, thus, it considers all deviations from the efficiency frontier to be due to inefficiency (i.e. it could also not isolate technical efficiency from random 
noise). Second, in the DEA model, biased efficiency estimates can be obtained due to inclusion or exclusion of certain health input and output variables. Third, estimates of DEA are extremely sensitive to outliers and measurement error, and biased efficiency estimates can be obtained due to inclusion or exclusion of certain health input and output variables in the DEA analysis. Fourth, and more importantly, in our analysis we consider that the Ethiopian regional health posts are identical, which might not be useable since working schedules, quality of delivery in healthcare services, healthcare technology, and the degree of severity of cases treated, among others, could significantly differ across regional health posts across the country. Five, we also failed to compare how efficient the program is compared with other Sub-Saharan African countries that have similar programs. Lastly, due to lack of input of prices information, estimates of the allocative and economic efficiency of the health posts were not performed. Therefore, further research work is essential to update the findings of this study on a large-scale, including Sub-Saharan African countries, to examine the evolution of the efficiency of community-based health workers program and make comparative studies.

\section{Acknowledgement}

We would like to thank the Ethiopian regional health bureaus for the provision of available data. Also, we would like to thank Dr. Munner Babu for his overall support of this paper.

\section{Funding}

We have received partial financial support from Adigrat University (ADU) allotted to Ph.D. students. However, the content of the study is exclusively the responsibility of the authors and does not necessarily represent the official views of the regional health bureaus (Ethiopia) and ADU.

\section{Availability of data and materials}

The datasets considered for this study can be provided or made by the corresponding author of the paper on reasonable request.

\section{Authors' contribution}

YH Gebresilassie has carried out the statistical data analysis, interpretation of the findings, reviewed related literature and drafted the article. PN has pointed out her critical comments on the findings of the study. Overall, both authors have carefully read and approved the final article. The authors declared that they have no competing interests.

\section{Ethics approval and consent to participate}

A letter of ethical approval of this study was obtained from the "Humanities and Social Science Research Ethics Committee" with a protocol reference number: HSS/0981/015D at the University of KwaZulu-Natal (UKZN), South Africa. 
Efficiency of the Ethiopian Health Extension Program: An Application of Data Envelopment ...

\section{References}

Amado, C. A. d. E. F. , \& Santos, S. P. d. (2009). Challenges for performance assessment and improvement in primary health care: the case of the Portuguese health centres. Health policy, 91(1), 43 - 56. Retrived from http://ac.els-cdn.com/S0168851008002595/1-s2.0S0168851008002595-main.pdf? tid=9b436df0-95b0-11e4-a2f400000aabOf27\&acdnat=1420554828 91252d690333400adf028b7b8b3f4d27.

Aristovnik, A. (2015). Regional Performance Measurement of Healthcare Systems in the EU: A Non-parametric Approach. Lex Localis, 13(3), 579 - 593. https://doi.org/10.4335/13.3.579$\underline{\text { 593(2015) }}$

Bhatia, A. , \& Mahendru, M. (2015). Assessment of Technical Efficiency of Public Sector Banks in India Using Data Envelopment Analysis. Eurasian Journal of Business and Economics, 8(15), 115-140. https://doi.org/10.17015/ejbe.2015.015.06

Bhattacharji, S. , Abraham, S. , Muliyil, J. P. P. , Job, J. S. , John, K. , \& Joseph, A. (1986). Evaluating Community health workers performance in India. Health Policy and Planning, 1(3), 232-239. https://doi.org/10.1093/heapol/1.3.232

Bilal, N. K. , Herbst, C. H. , Zhao, F. , Soucat, A. , \& Lemiere, C. (2011). Health extension workers in Ethiopia: improved access and coverage for the rural poor. Yes Africa Can: Success Stiroes from a Dynamic Continent, 433 - 443.

Charnes, A. , Cooper, W. W. , \& Rhodes, E. (1978). Mesuring the efficiency of decision making units. European journal of operational research, 2, 429-444. https://doi.org/10.1016/0377-2217(78)90138-8

Cheng, Z. , Tao, H. , Cai, M. , Lin, H. , Lin, X. , Shu, Q. , \& Zhang, R. (2015). Technical efficiency and productivity of Chinese county hospitals: an exploratory study in Henan Province, China. BMJ open, 5(9), e007267. https://doi.org/10.1136/bmjopen-2014-007267

Christopher, J. B. , Le May, A. , Lewin, S. , \& Ross, D. A. (2011). Thirty years after Alma-Ata: a systematic review of the impact of community health workers delivering curative interventions against malaria, pneumonia and diarrhoea on child mortality and morbidity in sub-Saharan Africa. Hum Resour Health, 9(1), 27. https://doi.org/10.1186/1478-4491-9-27

CNHDE. (2011). Ethiopia Health Extension Program Evaluation Study, 2007-2010, Volume-II. Health post and HEWs performance Survey. Addis Ababa, Ethiopia: Center for National Health Development in Ethiopia (CNHDE), Columbia University.

Coelli, T. , Battese, G. , Rao, D. S. , \& O'Donnell, C. J. (1998). An Introduction to Efficiency and Productivity Analysis (2 Edition ed.). USA: Springer

Coelli, T. J. (1996). A Guide to DEAP Version 2.1: A Data Envelopment Analysis (Computer) program'. CEPA Working Paper 96/08, Centre for Efficiency and Productivity Analysis (CEPA), Department of Econometrics, University of New England, Armidale, NSW, 2351.

Cooper, W. W. , Seiford, L. M. , \& Tone, K. (2006). Introduction to data envelopment analysis and its uses: with DEA-solver software and references. New York:: Spring

Cooper, W. W. , Seiford, L. M. , \& Tone, K. (2007). Data Envelopment Analysis: A Comprehensive Text with Models, Applications, References and DEA-Solver Software (Vol. second edition). New York, USA: Springer.

Debasish, S. S. (2006). Efficiency performance in Indian banking-Use of data envelopment analysis. Global Business Review, 7(2), 325-333. https://doi.org/10.1177/097215090600700209 
Dynes, M. , Buffington, S. , \& Carpenter, M. (2012). Strengthening maternal and newborn health in rural Ethiopia: Early results from frontline health worker community maternal and newborn health training. Midwifery.

Eunice, H. O. (2013). Data for Efficiency: A tool for Assessing Health Systems' Resource Use Efficiency. Bethesda, MD: Health Finance \& Governance Project, Abt Associates Inc.

Evans, D. B. , Tandon, A. , Murray, C. J. L. , \& Lauer, J. A. (2001). The Comparative Efficiency of National Health Systems in Producing Health: An Analysis of 191 Countries. GPE Discussion Paper Series No. 29. Geneva: WHO, EIP/GPE/EQC.

Fare, R. , Shawna, G. , Bjorn, L. , \& Pontus, R. (1989). Productivity Developments in Swedish Hospitals: A Malmquist Output Index Approach. Mimeo.

Farrell, M. J. (1957). The Measurement of Productive Efficiency. Journal of the Royal Statistical Society. Series A (General), 120(3), 253 - 290. https://doi.org/10.2307/2343100

FMoH. (2006/07). Health and Health Related Indicators. Addis Ababa, Ethiopia

FMoH. (2013/14a). Health Sector Development Program (HSDP) IV. Annual Performance Report. Addis Ababa, Ethiopia.

FMoH. (2013/14b). Health Sector Development Program (HSDP) IV. Annual Performance Report. Addis Ababa, Ethiopia. Retrieved from

FMoH. (2015). Health Extension Program: Profile. Addis Ababa, Ethiopian: The Federal Democratic Republic of Ethiopia Ministry of Health.

Gibril J. , Norashldah M. N. , Judhiana A.G. , \& A.J., s. (2015). Technical Effiiency of Secondary Health Care Service Delivery in the Gambia. International Journal of Economics and Management, 9(1), 25-43.

Grifell-Tatje, E. , \& Lovell, C. A. K. (1996). Deregulation and Productivity Decline: The Case of Spanish Savings Banks. European Economic Review, 40(6), 1281-1303. https://doi.org/10.1016/0014-2921(95)00024-0

HEPCAPS1. (2012). Ethiopia's Health Extension Platform: A background paper prepared for the HEPCAPS1 project. Ethiopia HEPCAPS1 Series Paper \#1. Boston, Massachusetts and New Haven, Connecticut: Harvard School of Public Health and Yale Global Health Leadership Institute.

Herna'ndez, A. R. , \& Sebastia'n, M. S. (2014). Assessing the technical efficiency of health posts in rural Guatemala: a data envelopment analysis. Global health action, 7, 221 - 230. https://doi.org/10.3402/gha.v7.23190

Jacobs, R. , Peter C., S. , \& Andrew, S. (2006). Measuring Efficiency in Health Care: Analytic Techniques and Health Policy: Cambridge University Press. https://doi.org/10.1017/CBO9780511617492

JarJuEa, G. , Mohamed Nor, N. , Abdul Ghani, J. , \& Abd Jalil, S. (2015). Technical efficiency of secondary health care service delivery in the Gambia. International Journal of Economics and Management, 9(1), 25-43.

Jayaraman, A. R. , \& Srinivasan, M. R. (2014). Performance Evaluation of Banks in India-A Shannon-DEA Approach. Eurasian Journal of Business and Economics, 7(13), 51-68.

Kakeman, E. , Forushani, A. R. , \& Dargahi, H. (2016). Technical Efficiency of Hospitals in Tehran, Iran. Iranian journal of public health, 45(4), 494-502. 
Efficiency of the Ethiopian Health Extension Program: An Application of Data Envelopment ...

Kathuria, V. , \& Sankar, D. (2005). Inter-State Disparities in Health Outcomes in Rural India: An Analysis Using a Stochastic Production Frontier Approach. Development Policy Review, 23(2), 145-163. https://doi.org/10.1111/i.1467-7679.2005.00280.x

Kengil B.C. , Gökmen N. , \& H., T. (2010). Efficiency Measures In The Health Services WITH Dea - An Overview. Journal of Naval Science and Engineering, 6(1), 1-14.

Kirigia, J. M. , \& Asbu, E. Z. (2013). Technical and scale efficiency of public community hospitals in Eritrea: an exploratory study. Health economics review, 3(1), 6. https://doi.org/10.1186/2191-1991-3-6

Kirigia, J. M. , Emrouznejad, A. , Sambo, L. G. , Munguti, N. , \& Liambila, W. (2004). Using data envelopment analysis to measure the technical efficiency of public health centers in Kenya. Journal of Medical Systems, 28(2), 155-166. https://doi.org/10.1023/B:JOMS.0000023298.31972.c9

Kirigia, J. M. , Emrouznejad, A. , Vaz, R. G. , Bastiene, H. , \& Padayachy, J. (2007). A comparative assessment of performance and productivity of health centres in Seychelles. International Journal of Productivity and Performance Management, 57(1), 72 - 92. https://doi.org/10.1108/17410400810841245

Kirigia, J. M. , Sambo, L. G. , Renner, A. , Alemu, W. , Seasa, S. , \& Bah, Y. (2011). Technical efficiency of primary health units in Kailahun and Kenema districts of Sierra Leone. Int Arch Med, 4(15), 125 - 140. https://doi.org/10.1186/1755-7682-4-15

Kumar, S. , \& Gulati, R. (2008). An examination of technical, pure technical, and scale efficiencies in Indian public sector banks using data envelopment analysis. Eurasian Journal of Business and Economics, 1(2), 33 - 69.

Lemma, H. , \& Sebastian, M. S. (2010). Efficiency of the health extension programme in Tigray, Ethiopia: a data envelopment analysis. BMC international health and human rights, 10(16).

Marschall, P. , \& Flessa, S. (2009a). Assessing the efficiency of rural health centres in Burkina Faso: an application of Data Envelopment Analysis. Journal of Public Health, 17(2), 87 - 95. https://doi.org/10.1007/s10389-008-0225-6

Marschall, P. , \& Flessa, S. (2009b). Assessing the efficiency of rural health centres in Burkina Faso: an application of Data Envelopment Analysis. Journal of Public Health, Springer Verlag, 17(2), 87-95. https://doi.org/10.1007/s10389-008-0225-6

Mogha, S. K. , Yadav, S. P. , \& Singh, S. (2014a). Estimating technical and scale efficiencies of private hospitals using a non-parametric approach: case of India. International Journal of Operational Research, 20(1), 21-40. https://doi.org/10.1007/s13198-013-0207-0

Mogha, S. K. , Yadav, S. P. , \& Singh, S. (2014b). New slack model based efficiency assessment of public sector hospitals of Uttarakhand: state of India. International Journal of System Assurance Engineering and Management, 5(1), 32-42. https://doi.org/10.1504/IJOR.2016.074759

Mogha, S. K. , Yadav, S. P. , \& Singh, S. (2016). Estimating technical efficiency of public sector hospitals of Uttarakhand (India). International Journal of Operational Research, 25(3), 371399.

Murray, C. J. L. , \& Frenk, J. (1999). A WHO Framework for Health System Performance Assessment: Global Programme on Evidence and Information for Policy. Retrieved from Washington DC, 
Perry, H. , Zulliger, R. , Scott, K. , Javadi, D. , \& Gergen, J. (2013). Case Studies of Large-Scale Community Health Worker Programs: Examples from Bangladesh, Brazil, Ethiopia, India, Iran, Nepal, and Pakistan. Retrieved from

Ray, S. C. (2004). Data envelopment analysis: theory and techniques for economics and operations research: Cambridge university press Cambridge.

Renner, A. , Kirigia, J. M. , Zere, E. A. , Barry, S. P. , Kirigia, D. G. , Kamara, C. , \& Muthuri, L. H. (2005). Technical efficiency of peripheral health units in Pujehun district of Sierra Leone: a DEA application. BMC Health Services Research, 5(1), 77. https://doi.org/10.1186/14726963-5-77

SCRCSSP. (1997). Data Envelopment Analysis: A technique for measuring the efficiency of government service delivery, by Steering Committee for the Review of Commonwealth/State Service Provision (SCRCSSP), AGPS, Canberra. Retrieved from

Sharma, R. , Webster, P. , \& Bhattacharyya, S. (2014). Factors affecting the performance of community health workers in India: a multi-stakeholder perspective. Global health action, 7(25352).

USAID. (2008). Working toward the goal of reducing maternal and child mortality: USAID programming and response to FY08 appropriations.

WHO. (1989). Strengthening the performance of community health workers in primary health care. Report of a WHO Study Group. Geneva, World Health Organization (WHO Technical Report Series, No. 780). [meeting held in Geneva from 2 to 9 December 1987].

WHO. (2000). Health Systems: Improving Performance. Geneva: WHO.

Worthington, A. C. (2004). Frontier efficiency measurement in health care: a review of empirical techniques and selected applications. Medical care research and review, 61(2), 135-170. https://doi.org/10.1177/1077558704263796 